\title{
A MEDICALIZAÇÃO DO PARTO E SUAS CONŞEQÜÊNCIAS: O EXEMPLO DA FRANÇA NO
PERÍODO ENTRE AS DUAS GUERRAS
}

FRANÇOISE THÉBAUD Université d'Avignon

Resumo: Na história da medicalização do parto, o período entre as duas guerras (1919-1939) aparece na França como um período de transição. Em um contexto de fraca natalidade, produziu-se nesse período, notadamente nas grandes cidades, a transferência de um número crescente de parturientes para as maternidades hospitalares que ofereciam cada vez mais segurança. Desenvolve-se aí então uma rede de consultas pré e pós-natais para acompanhar a gravidez e os cuidados com os bebês. O objetivo era salvar as mães e sobretudo as crianças. Enquanto que as parteiras temiam o declínio de sua profissão, o objetivo foi apenas parcialmente alcançado, porque a medicalização do parto e da função materna encontrou resistências e limites: o peso dos hábitos sociais e culturais, a insuficiência da proteção social da maternidade, as dificuldades das condições de vida de certas camadas da população, a ausência de uma rede coordenada de consultas para mulheres grávidas e recém-nascidos, uma distribuição muito desigual no território francês desses serviços, o apego das profissões de saúde ao exercício liberal e o medo da influência do Estado...

Palavras-chave: parto, maternidade hospitalar, parteira, consultas pré e pós-natais, mortalidade materna e infantil.

No século XIX, em uma França ainda fortemente rural, a grande maioria das francesas dava à luz em casa, com assistência médica (para as mais abastadas) ou sem. Somente as mulheres pobres da cidade ou as mães solteiras, que queriam esconder sua gravidez ou não sabiam aonde ir, vinham ao hospital e pagavam um pesado tributo às epidemias de febre puerperal. ${ }^{1}$ Hoje, todas as francesas, salvo própria escolha, buscam o conforto e a segurança oferecidos pelos serviços das maternidades onde trabalham parteiras e médicos obstetras, estes últimos requisitados para os casos mais complexos ou intervenções ditas de 'atendimento particular' e pagas pela parturiente.

O parto é hoje um ato médico praticado em lugares muito medicalizados, colocando no mundo com a maior segurança crianças que foram, na maioria dos casos, desejadas por seus pais. Isso é o resultado de um século de transformações sociais, descobertas

Copyright (C) 2002 by Revista Estudos Feministas

1 Ver Scarlet BEAUVALET-BOUTOUYRIE, 1999. A autora analisou a Maternidade de Port-Royal em Paris. Existem poucos trabalhos de pesquisa sobre as realidades das províncias ou do campo na França. 
científicas e conquistas políticas (sobretudo o controle dos nascimentos) ${ }^{2}$ ocorridas em épocas diferentes. Antes das revoluções maternas do pós- $1945,{ }^{3}$ o período entre as duas guerras aparece como um período de transição, merecendo ser analisado para que se compreenda a implantação e os efeitos da medicalização do nascimento. ${ }^{4}$

\section{O contexto francês: 'salvar a raça'}

A França ganhou a guerra de 1914-1918 e recuperou os territórios da Alsácia-Lorena perdidos em 1871. Porém, uma parte de suas elites, obcecada pela decadência, evocou rapidamente "a outra guerra" a travar ("a guerra contra os inimigos internos: despovoamento, alcoolismo, tuberculose, sífilis"), explicando que a seus olhos o problema "não é saber como a França viverá, mas como ela não morrerá". ${ }^{5}$ Acontece que o conflito foi uma verdadeira catástrofe demográfica (mais de um milhão e meio de militares, várias centenas de milhares de civis mortos, grande déficit dos nascimentos), em um país transformado, cronologicamente e em razão da amplitude do fenômeno, no primeiro país malthusiano da Europa. Já perceptível na segunda metade do século XIX, a diminuição dos nascimentos acentuou-se no período entre as duas guerras e particularmente nos anos 1930, quando chegaram à idade adulta les classes creuses ${ }^{6}$ da Primeira Guerra, em um contexto de crise econômica e de tensão internacional. A taxa de natalidade que era de 21,4 por mil em 1920, caiu para 18,3 em 1928 e para 14,6 em 1938. A mortalidade recuava lentamente, e os nascimentos eram menos numerosos do que as mortes a partir de 1935; em 1938 o déficit anual atingiu 35 mil, quando então a população (41,9 milhões) era apenas um pouco maior do que em 1911, para a mesma superfície que incluía os territórios da Alsácia-Lorena, antes pertencentes à Alemanha.

Nesse contexto, os poderes públicos se tornaram cada vez mais sensíveis aos argumentos e às reivindicações dos movimentos pela natalidade (como a Aliança Nacional para o Crescimento da População Francesa - Alliance Nationale pour l'Accroissement de la Population Française), que denunciavam o perigo do poder demográfico do 'inimigo hereditário' alemão. Em diversas medidas, eles adotaram pouco a pouco um programa feito de repressão e de estímulos: repressão das práticas abortivas e contraceptivas assim como de toda propaganda sobre o controle dos nascimentos, estímulo através de homenagens às mães (medalhas e monumentos) e ajuda financeira às famílias (sobretudo com a lei de 11 de março de 1932, que tornou obrigatório o pagamento de abonos familiares aos assalariados responsáveis por crianças). Essa política, que culminou no decreto-lei de 29 de julho de 1939, chamado de Código da Família, foi entretanto impotente para mudar a distribuição demográfica antes do baby-boom do pós-1945: as francesas tinham poucos filhos, os casais franceses rejeitavam as 'famílias numerosas', que a partir de então foram definidas pela existência de pelo menos três filhos.

\footnotetext{
${ }^{2}$ Ver Janine MOSSUZ-LAVAU, 1991, e Xavière GAUTIER, 2002.

${ }^{3}$ Ver Yvone KNIBIEHLER, 1997.

${ }^{4}$ A principal fonte deste artigo é minha tese defendida em 1982 e publicada de forma resumida em 1986 (THÉBAUD, 1986). Por solicitação de Lucia Mott, eu a reli à luz dos trabalhos mais recentes que tratam sobretudo do século XIX ou do pós-1945.

${ }^{5}$ Georges CAHEN, 1920.

- Les classes creuses é uma expressão usada pelos demógrafos para designar os grupos por idade (anual ou qüinqüenal) pouco numerosos, quando a natalidade foi baixa em um certo momento. Durante a Primeira Guerra Mundial os nascimentos diminuíram. Vinte anos mais tarde, os adultos em idade de procriar eram, portanto, pouco numerosos.
} 
Se a injunção pró-natalidade ('é preciso fazer nascer') era difícil de ser posta em prática, era possível, segundo uma outra corrente mais eclética, preservar a criança concebida e a criança nascida, 'salvar a raça', diminuindo o número de abortos espontâneos e as taxas de mortalidade infantil. Essa corrente, que pode ser qualificada de realista, era formada por políticos, filantropos, higienistas, entre os quais numerosos médicos e notadamente médicos-parteiros como Adolphe Pinard ou seu genro Alexandre Couvelaire. Ela recebeu o apoio da maioria moderada do movimento feminista que militava pela emergência de um Estado-providência, maternal em relação aos mais frágeis. ${ }^{7}$ Essa corrente se desenvolveu no período do surgimento da higiene social que tinha por objetivo submeter a população a um controle médico generalizado e melhorar seu estado de saúde lutando contra os 'flagelos sociais': um serviço nacional do mesmo nome foi criado em 1923, assim como uma rede de dispensários e uma revista. Paralelamente, os serviços de seguridade social, orgulho do jovem Estado-providência, implantados após longos debates, por uma lei em 1930, permitiram o acesso de novas camadas da população a cuidados mais exigentes, fora da assistência, contribuindo para a medicalização da sociedade: por exemplo, no pagamento das prestações do seguro-maternidade propunha-se não somente condições de cotização (as duas taxas, salarial e patronal, eram em média de $4 \%$ ), como também, no período entre as duas guerras, um teto de salário, e a participação em consultas médicas pré e pós-natais. ${ }^{8}$ Os hospitais, que passaram a oferecer técnicas cada vez mais eficazes, e em alguns deles um conforto aceitável, ocuparam um espaço maior no sistema sanitário com a duplicação, entre 1901 e 1941, dos doentes anualmente hospitalizados.

Após a era dos pioneiros que impuseram, como Tarnier (1828-1897), a anti-sepsia na sala de parto ou, como Paul Strauss, a assistência às mulheres no parto, proteger a maternidade tornou-se um imperativo determinate do período entre as duas guerras. Fora medidas sociais, a proteção da maternidade significou sua medicalização, essencialmente através da instituição-Maternidade.

\section{Dar à luz na maternidade: uma prática cada vez mais freqüente, porém desigualmente distribuída}

Nenhum trabalho, até onde eu saiba, recenseou os leitos de maternidade disponíveis na França do período entre as duas guerras. Se o sonho racional dos altos funcionários do Ministério da Saúde Pública dos anos 1930 estava longe de ser realizado, a oferta cresceu com a ampliação do número de leitos ou de novos serviços de assistência ao parto, tendência esboçada desde a criação do corpo de parteiros dos hospitais, em 1881. Porém, a melhora da qualidade ocorreu com a reorganização, nos anos 1920, em Paris, da Maison d'Accouchement Baudelocque (Casa de Parto Baudelocque), que passa a ser o modelo das novas maternidades. Segundo estabelecimento especializado da capital, ao lado da velha Maternidade de Port-Royal, ela foi construída no fim do século XIX dentro das novas exigências da anti-sepsia, e inaugurada em 1890 com o nome de "Maison d'Accouchement Baudelocque, clínica obstétrica da Faculdade de Medicina de Paris", sendo sua cátedra confiada a Adolphe Pinard. Após a guerra, o estabelecimento passou por grandes reformas, que traduziram arquitetonicamente a racionalização de seu funcionamento e ganhou 0 nome de "Maternidade Baudelocque". Como explicou, em 1930, o parteiro daquela

\footnotetext{
7 Ver Anne COVA, 1997, e Evelyne DIEBOLT, 2001.

${ }^{8} \mathrm{~A}$ seguridade social reembolsava, em parcelas, os gastos referentes aos partos das mulheres dos associados e das assalariadas associadas; estas últimas, além da vantagem de receberem, durante 12 semanas, pagamento de auxílios diários iguais a quase metade de seus salários, podiam ainda receber abonos mensais pelo aleitamento.
} 
instituição, Alexandre Couvelaire, "uma maternidade não deve ser somente uma casa de parto, mas sim um centro de assistência médico-social e de trabalho científico consagrado à função da reprodução". ${ }^{9}$ Oferecendo múltiplos serviços (consultas pré-nupciais, consultas ginecológicas, consultas pré e pós-natais, dispensário anti-sifilíitico, centro obstétrico para tuberculosas, lactário, serviço social), seu campo de ação estende-se da procriação ao desmame da criança, tornando-se uma escola para as mães e para o pessoal que se especializava em puericultura. As salas de parto para atendimento individual deram fama à Maternidade. Entretanto, estavam bem longe de se tornarem regra, e em numerosos serviços hospitalares, do período entre as duas guerras, faltavam não só conforto como higiene. Em 1938, Le Journal de la Femme (O Jornal da Mulher), fazendo uma pesquisa sobre a assistência materna, considerava que os maiores progressos estavam relacionados às maternidades, tendo o futuro médico Alexandre Valero Bernal defendido uma tese entusiasmada sobre "as maternidades, a puericultura e a profilaxia". Mas a diversidade da oferta, mal conhecida, aliás, nas cidades de porte médio, permaneceu grande e refletiase na diversidade das práticas sociais, enquanto que a imagem do hospital parecia evoluir menos rapidamente do que sua realidade.

Onde então davam à luz as francesas, no período entre as duas guerras? Qual era o público das maternidades? Faltam-nos respostas numéricas em escala nacional porque a série Mouvement de la Population (Movimento da População) da estatística geral da França só possui dados sobre local de parto até 1931. Esses dados, que reúnem sem distinção os partos "em um estabelecimento ou em casa de uma parteira" (sendo "em casa" ou "não declarado" as outras categorias), são, sem dúvida, mais indicativos do que rigorosos. Indicam não só a importância do parto domiciliar como o início, nos anos 1920, de um lento recuo. Vale destacar que em 1931 o parto domiciliar ainda ultrapassava a taxa dos $80 \%$. Ora, as estatísticas da Caixa Nacional de Seguros de Doença (Caisse Nationale d'Assurances Maladie), que são consideradas confiáveis, registravam $47 \%$ de partos em casa, em 1952. Nos anos 1930, verifica-se um grande movimento das parturientes na direção dos hospitais, que foi acelerado pela crise da habitação decorrente da Segunda Guerra e pela década do baby-boom. Em 1962, somente $15 \%$ dos partos eram no domicílio Para definir o papel desempenhado pelas maternidades e introduzir a variável geográfica e social, é preciso, entretanto, mudar de escala.

Paris, sem dúvida, colocou-se na dianteira do movimento: entre 1920 e 1939 , segundo os Annuaires Statistiques de la Ville de Paris (Anuários Estatísticos da Cidade de Paris), os partos em maternidade ${ }^{10}$ dobraram para atingir $68 \%$; os partos domiciliares recuaram muito, de $42 \%$ para $8 \%$, e os partos domiciliares realizados por parteira oscilaram em torno de $24 \%$. No fim dos anos 1930 , a Maternidade Baudelocque realizava aproximadamente 3 mil partos por ano, e as maternidades da AP (Assistência Pública) acolhiam mais de 80 mulheres por dia e faziam anualmente mais de 120 mil consultas de mulheres grávidas e recém-nascidos, difundindo, ajudadas por numerosas obras particulares, o discurso de uma puericultura muito normativa. Mas Paris, onde os hospitais recebiam cada vez menos mulheres vindas de fora para esconder sua gravidez (recuo da taxa de nascimentos ilegítimos entre essas mulheres), acentuava essa tendência e não representava a França. O departamento do Sena (do qual Paris é a capital), que concentrava, em 1935, 12\% da população francesa, possuía a maior taxa das consultas

\footnotetext{
${ }^{9}$ Alexandre COUVELAIRE, 1930.

${ }^{10}$ O serviço da Assistência Pública de Paris era constituído, no fim do período, de três estabelecimentos especializados e de 11 maternidades hospitalares.
} 
nacionais e $30 \%$ dos serviços de assistência ao parto. " O interior contava somente com 352 serviços públicos de assistência ao parto instalados nas cidades médias e grandes. Observando-se a situação rural e a situação da cidade de Saint-Etienne (cidade industrial e mineira de 150 mil habitantes, no centro da França), ${ }^{12}$ é possível perceber a especificidade da situação parisiense e a persistência, até depois da Segunda Guerra, do antigo modelo de parto domiciliar, que escapava em grande parte da ação médica.

No campo, quase todas as mulheres davam à luz em casa e freqüentemente sem a ajuda da Faculdade de Medicina. O programa apresentado pelo médico-parteiro parisiense Louis Devraigne em 1922 ("fazer desaparecer as comadres, multiplicar os cargos para parteiras formadas, criar em todos os lugares possíveis pequenas maternidades do tipo daquelas que funcionavam nos países devastados pela guerra") ${ }^{13}$ só foi realizado 15 anos mais tarde. Um quarto dos cantões não possuía parteira diplomada e as maternidades rurais eram exceção: havia nove pequenos estabelecimentos construídos no início dos anos 1920, por iniciativa privada da Mutualité Maternelle de Paris (Associação de Previdência Materna de Paris), nos departamentos do norte e do leste devastados pela guerra; uma pequena maternidade de três leitos aberta pela mesma iniciativa na Normandia, em 1929; algumas maternidades anexas aos hospitais cantonais. Em uma tese de medicina defendida em 1948, um futuro médico pertencente à elite alertava seus colegas sobre a ausência de proteção materna e infantil no meio rural, lançando, sobre "os bárbaros do campo", as casas e os corpos sujos, o olhar de desprezo de um importante habitante da cidade. ${ }^{14} \mathrm{Na}$ verdade, se o parto em maternidade era uma realidade urbana, as consultas pré-natais e de recém-nascidos, que constituíam uma das vias paralelas do processo de medicalização, atingiram uma população mais numerosa. Implantadas, também nos estabelecimentos hospitalares ou maternidades em funcionamento, pelas municipalidades ou por iniciativas privadas, essas consultas eram certamente mal distribuídas no território e insuficientes, porém existiam em quase todos os departamentos e em número crescente. Foram feitas 400 consultas de mulheres grávidas em 1926 e mais de mil em 1935; 494 consultas de recém-nascidos em 1907, 3.715 em 1928, e aproximadamente 5 mil em 1937.

Em Saint-Etienne, uma das poucas cidades do interior estudadas sob esse ângulo, ${ }^{15}$ a oferta de cuidados e as práticas sociais mudaram muito entre 1914 e 1936, porém o parto domiciliar ainda prevaleceu após a Segunda Guerra. A transferência do parto para as maternidades aconteceu como em Paris, mas com menor amplitude e com uma defasagem cronológica. Em 1914, a maternidade do Hospital de Bellevue, daquela cidade, construída em 1900 e que acabava de contratar seu primeiro parteiro, realizou $16 \%$ dos nascimentos. A abertura, nesse mesmo ano, da Casa Familiar do Rhône (Maison Familiale du Rhône) ${ }^{16}$ transformou-se rapidamente, sob a direção de um renomado parteiro (o doutor Pelissier), de um refúgio para mães solteiras em uma casa maternal moderna, atraindo

\footnotetext{
"Essa taxa de $30 \%$, como o número seguinte de 352 serviços de maternidade nas províncias, devem ser vistos com cautela. Os dados obtidos na aula inaugural de um professor de medicina proferida em 2 de dezembro de 1937, e em um número do Bulletin de l'Association Française des Femmes Médecins (Boletim da Associação das Mulheres Médicas), não puderam ser verificados, e a definição de 'serviço de maternidade' não estava clara.

${ }_{12}$ Mathilde DUBESSET e Michelle ZANCARINI-FOURNEL, 1993.

${ }^{13}$ Relatório apresentado ao Comité Nacional da Infância. Louis Devraigne é médico-parteiro no hospital Lariboisière.

${ }^{14}$ Philippe CRIVELLI, 1948.

${ }^{15}$ DUBESSET e ZANCARINI-FOURNEL, 1993. A obra citada contém uma terceira parte intitulada "Maternidades" e m capítulo da quarta parte intitulado "Sage-femme, um métier du féminin".

${ }^{16}$ Rhône é o departamento cuja capital é Saint-Etienne.
} 
uma nova clientela. Nos anos 1920, a proporção dos nascimentos em maternidade dobrou, atingindo $46 \%$, em 1946, incluindo os partos em clínica particular. Os dois principais estabelecimentos faziam concorrência entre si, mas, para os habitantes de Saint-Etienne, o hospital, a despeito de suas transformações, ainda conservava uma imagem negativa, como sendo um lugar onde havia morte e pobres.

À diferença geográfica certamente deve ser acrescida a diferença social, que é possível de ser percebida pela pesquisa nos registros de entradas e de nascimentos dos estabelecimentos. ${ }^{17}$ O perfil social da clientela da Maternidade Baudelocque e de Bellevue de Saint-Etienne se transformou no período entre as duas guerras. Inicialmente havia um número maior de mulheres casadas em detrimento das mães solteiras: a taxa de casadas passou de $61 \%$ para $81 \%$, entre 1919 e 1939 , e de $51 \%$ para $85 \%$, entre 1919 e 1946 . Mas a Maternidade Baudelocque continuava fazendo o papel de maternidade secreta onde era possível esconder a gravidez e fazer as mães solteiras aproveitarem uma estadia na casa maternal de Saint-Maurice, de regulamento quase carceral. ${ }^{18} \mathrm{~A}$ casa maternal de Saint-Etienne também acolhia prioritariamente mães solteiras, mas seu número era minoritário no conjunto da clientela, e a instituição procurava combater o abandono de crianças. No período ocorreu ainda uma outra transformação, que se deu de forma mais lenta: a clientela se diversificou, abrangendo uma fração cada vez menos negligenciável de mulheres oriundas das camadas médias (professoras primárias, comerciantes, datilógrafas), permanecendo, entretanto, majoritariamente popular, com uma forte representação de empregadas domésticas e operárias, ou de mulheres de operários e artesãos. Após 1930, o número de mulheres portadoras de seguro social atingiu e ultrapassou rapidamente a metade das parturientes. Porém, se os seguros sociais representaram um estímulo para que as mulheres que tinham uma imagem positiva das maternidades procurassem atendimento na instituição, as outras, aquelas que iam por necessidade, preferiam fazer um pequeno esforço financeiro e dar à luz em suas casas, 'como as ricas'.

A partir da análise de textos e de depoimentos orais, verifica-se que a imagem do hospital permanecia ambígua, na medida em que não havia, então, entre os profissionais de saúde, um consenso sobre o local ideal para o parto. As duas práticas (parto domiciliar e parto em maternidade), ou mesmo as três práticas (acrescentando-se o parto em uma pequena casa de parto mantida por uma parteira), coexistiram, sendo defendidas e combatidas por diferentes grupos. Muitos homens e mulheres aderiram à ideologia familiar e pró-natalista, elaboraram argumentos de ordem moral e denunciaram os riscos para $o$ lar de um parto fora de casa ou a 'contaminação moral em razão da promiscuidade'. Acrescentaram também argumentos de ordem profissional: médicos da cidade temiam se tornar funcionários do hospital e as parteiras temiam perder a clientela e a autonomia.

\section{As parteiras: uma profissão em crise?}

O século XIX havia sido um período mais favorável para as parteiras. Apesar do confisco pelos homens do ensino obstétrico, a prática do parto permanecia como uma especialidade dessas profissionais. Beneficiando-se dos esforços dos poderes públicos para prestarem assistência às parturientes, e do pudor feminino, o número de parteiras havia aumentado ao longo do século, ultrapassando 14 mil em 1891. A criação do corpo dos médicos-parteiros e a lei de 30 de novembro de 1892 sobre o exercício da medicina, proibindo às parteiras o uso de instrumentos e a prescrição de medicamentos, marcaram

\footnotetext{
${ }^{17}$ As séries consultáveis são contínuas para Baudelocque e descontínuas para a Maternidade Bellevue de SaintEtienne.

${ }^{18}$ Saint-Maurice é uma comuna na periferia oeste de Paris.
} 
o início da diminuição. Em 1912, uma tese de medicina avaliava que o número de partos feitos por ano por uma parteira parisiense era de 15, número que levou algumas delas a dirigirem-se à prática ilegal dos abortos e a tornarem-se 'fazedoras de anjos'. Em 1938, foi realizado em Paris o $8^{\circ}$ Congresso Internacional das Parteiras. Melle Mossé, a parteirachefe da Maternidade de Paris, chamada de Port-Royal, a mais antiga e a maior da França, ao abrir o congresso, fez então um apelo à revalorização do papel social da "mais antiga das profissões femininas" e expôs os problemas profissionais enfrentados, destacando entre eles "a concorrência do grande número de médicos e da excessiva hospitalização". Quais eram exatamente os problemas? Tratava-se de uma verdadeira crise? De uma adaptação dolorosa às novas realidades da profissão? Da diversificação das modalidades e dos salários da profissão? ${ }^{19}$

Certamente, o desenvolvimento das maternidades reduziu a necessidade de parteiras e levou ao fechamento de alguns leitos nas casas de parto na cidade. Na Maternidade Baudelocque, em 1930, trabalhavam sete parteiras para mais de 3 mil admissões por ano, enquanto que uma pequena casa de parto empregava de uma a duas profissionais para 200 partos anuais. Assim, nomeadas por ocasião da grande epidemia de febre puerperal de 1867 para aliviar os serviços hospitalares, as parteiras agregadas pela Assistência Pública de Paris tornaram-se inúteis, e a última que trabalhou para a Maternidade Baudelocque fechou os poucos leitos em março de $1934 .^{20}$

Porém, o que mais incomodava a profissão era a concorrência de outras categorias: inicialmente os paramédicos; as enfermeiras, cujo diploma foi criado em 1922 (enfermeira hospitalar e visitadora sanitária) e cuja prática de visitas domiciliares quando feita à casa de uma grávida ou de uma jovem mãe competia com as atribuições da parteira; as assistentes sociais, cuja profissão foi regulamentada em 1932, pela instituição de um diploma. Vale destacar que as assistentes sociais foram acusadas de fazerem a 'propaganda contra o parto domiciliar' e de encaminharem as futuras mães para dispensários e maternidades. Porém, a concorrência maior era a dos médicos que dividiam com as parteiras o monopólio do parto. Eles, cada vez mais numerosos (12 mil em 1891, 20 mil em 1911, 26 mil em 1936), beneficiavam-se de trunfos inegáveis e apropriavam-se da parte das parteiras: em uma escala nacional, $75 \%$ dos partos no início dos anos 1920 , e aproximadamente $64 \%$ em 1931 ; em Paris, aproximadamente $70 \%$ na década de 1920 , e menos de $60 \%$ no fim da década seguinte. ${ }^{21}$ Mais ricos, os médicos dispunham de telefone e de automóvel, o que facilitava o contato com a clientela; somente eles tinham direito de utilizar oxitócicos e instrumentos durante os partos, e a lei relativa à Seguridade Social lhes reservava, fora das consultas conveniadas, os exames das mulheres grávidas.

Em um serviço hospitalar de maternidade, a concorrência masculina traduzia-se pela promoção do médico-parteiro, chefe de serviço e freqüentemente professor de clínica obstétrica e pela exclusão da parteira de um trabalho qualificado e do exercício do poder,

\footnotetext{
${ }^{19}$ Numerosos trabalhos de médicos, juristas, moralistas falam da profissão e do papel das parteiras. Os congressos nacionais e internacionais (das parteiras), assim como o Journal des Accoucheuses (boletim oficial da associação das parteiras e puericultoras da França), são fontes oriundas da profissão. Para situar a questão a longo termo, ver Jacques GELLIS, 1988.

${ }^{20}$ Nomeadas pelo diretor da Assistência Pública, as parteiras agregadas trabalhavam sob o controle dos parteiros, eram remuneradas pelo número de parturientes atendidas e dispunham de alguns leitos para receber pensionistas de quem faziam os partos e cuidavam no pós-parto.

${ }^{21}$ A fonte são os quadros de repartição dos nascimentos conforme a assistência recebida pela mãe, no Mouvement de la Population e nos Annuaires statistiques de la ville de Paris.
} 
para fazer dela uma auxiliar dedicada, 'uma espécie de enfermeira de qualidade superior', que deveria se preocupar menos com a ciência (masculina) e mais com os cuidados aos doentes, e saber exatamente 'o que ela não deveria fazer'. Porém, a realidade hospitalar acabava muitas vezes sendo bem diferente, e muitas iniciativas acabavam nas mãos das parteiras, que mantinham o controle e a responsabilidade da sala de trabalho, ensinavam as internas pouco competentes e pouco viam o médico-parteiro. Entrevistada no início dos anos 1980, uma antiga parteira dizia com orgulho, utilizando o masculino e o feminino: "as parteiras eram grandes mulheres (...) elas eram mestres e donas dos procedimentos na sala de trabalho".

A parteira era indispensável para a maternidade (menos de $5 \%$ das profissionais) e para a clientela. Primeiro, porque havia uma melhor distribuição geográfica dessas profissionais do que de médicos: os médicos residentes no departamento do Sena somavam $25 \%$ e as parteiras, $10 \%$, mesmo que muitas delas tivessem abandonando o duro trabalho de parteira rural, visto serem encontradas em apenas 500 dos 2.200 cantões. Em seguida, porque os médicos declaravam, eles mesmos, serem incapazes de permanecerem ao lado da parturiente durante todo o trabalho de parto, como escreveu Couvelaire na Presse Médicale (Imprensa Médica) de 19 de novembro de 1930: era preciso "mulheres formadas, capazes de acompanhar a conclusão de uma função que a cada momento pode deixar de ser fisiológica, capazes de permanecer longas horas na cabeceira das parturientes e de receber, da melhor forma possível, em suas mãos experientes, a criança às vezes mais apressada em nascer do que o médico em vir, dividido em suas múltiplas obrigações". Enfim, a parteira era indispensável porque o ensino obstétrico de um clínico geral era insuficiente e porque a maioria das francesas ainda recorria a elas, pois acreditavam que estavam melhor preparadas para assisti-las, sendo consideradas verdadeiras especialistas em partos. Desde a unificação da profissão em 1916 (dois anos de estudos após o diploma elementar, em uma escola ligada à faculdade de medicina) tinham boa formação.

Em Saint-Etienne, ser parteira com uma clientela no período entre as duas guerras era uma profissão reconhecida socialmente, uma das raras profissões exercidas por mulheres que eram relativamente lucrativas. As profissionais entrevistadas, em geral, expressavam um orgulho do passado, evocando a habilidade e desembaraço em diferentes situações e o papel de educadora dos princípios de higiene e de confidente, e nos mostravam freqüentemente a antiga placa afixada em sua casa ou a maleta de trabalho. ${ }^{22}$

Assim, mais do que falar da crise geral da profissão, vale ressaltar a diversidade das condições e a consciência de que a idade de ouro das parteiras acabou. No período entre as duas guerras, o número, que baixou muito entre 1911 e 1921, se estabilizou em torno de 11 mil, mas só uma parcela (2 mil, avalia um médico-parteiro) tinha um salário decente, entre as quais aquelas que ultrapassaram a linha dos assalariados. Pela falta de um número suficiente de clientes, avaliado em várias dezenas por ano, e pela diminuição da natalidade, que acrescentava seus efeitos às causas já evocadas (concorrência dos médicos, transferência dos partos para as maternidades), as outras tinham dificuldades para viver, principalmente quando eram solteiras (caso freqüente). Médicos, poderes públicos, organizações de parteiras falavam do número excessivo de parteiras e expressavam o desejo e formulavam projetos de reforma: admissão de alunas mais novas, recrutamento hospitalar por concurso, prolongamento dos anos de estudos, ampliação das atribuições para fazer das parteiras, ao mesmo tempo, parteiras e assistentes de

${ }^{22}$ Entrevistas realizadas nos anos 1980 por Mathilde Dubesset e Michelle Zancarini-Fournel (DUBESSET e ZANCARINIFOURNEL, 1993). 
proteção materna e infantil. Nenhuma reforma foi implantada antes da Segunda Guerra, diante da hostilidade das enfermeiras ou do excessivo apego ao exercício liberal da profissão. Porém, mesmo lentamente, as mentalidades se transformaram, como mostram as comunicações feitas no congresso de 1938, onde se discutia o papel social das parteiras como "controladoras vigilantes e informadas da maternidade", desde a concepção ao desmame (e não somente durante o parto e nos seus desdobramentos posteriores), e como colaboradoras indispensáveis das organizações sociais e das diversas obras de proteção da maternidade e da infância. Elas estavam mobilizadas, como outros grupos, na luta contra a mortalidade das mães e das crianças.

\section{Uma vitória sobre a morte das mães e das crianças?}

O objetivo da medicalização é salvar vidas de mães e, mais ainda, vidas de crianças. Desejamos, nas linhas seguintes, medir sua realização e explicar as causas de um relativo sucesso.

A mortalidade materna na França, ${ }^{23}$ que era de $3 \%$ aproximadamente no início do século XIX, recuou fortemente após 1860 , graças ao isolamento das mulheres infectadas $e$ à aplicação da anti-sepsia. Exceção feita aos anos do primeiro conflito mundial, ela diminuiu ainda pela metade, entre 1900 e 1925, para estabilizar-se em seguida entre 2 e 3 por mil, - que colocava a França entre os países de baixa taxa de mortalidade, como a ltália ou os Países-Baixos. Somente a Suíça conheceu taxas inferiores a 2 por mil, enquanto que nos Estados-Unidos a mortalidade materna era particularmente elevada (entre 6 e 7 por mil). A mortalidade das mulheres no parto variou também geograficamente, apresentando altas taxas nas cidades (sobretudo nas grandes cidades) em razão da freqüência dos abortos (fonte de infecção puerperal) e do aumento dos nascimentos ilegítimos. Entretanto, em Paris, onde a mortalidade materna era elevada no início dos anos 1920, decresceu para 1,4 por mil em 1938. Este é um contra-exemplo que mostra os benefícios da medicalização da assistência ao parto em grande escala: o acompanhamento da gravidez permitiu detectar as toxemias gravídicas, as más-formações, as gravidezes extra-uterinas. O parto passou a contar com melhores condições, e a infecção puerperal foi parcialmente vencida, causando menos de uma morte a cada duas.

Nos hospitais parisienses do período entre as duas guerras, a mortalidade materna variou, segundo os locais e os anos, entre 2,3 e 15 por mil. Na Maternidade Baudelocque, onde as teses de medicina permitem o cálculo até 1931, a taxa de mortalidade por infecção puerperal era baixa (0,9 por mil, em 1921; 1,7 por mil, em 1927) porque o estabelecimento, concebido sobre o princípio da separação das funções, permitia o isolamento das mulheres doentes ou em observação. Porém, a mortalidade geral permaneceu elevada e flutuante entre 6,3 por mil e 14,5 por mil, em 1931, bem superior à do hospital Boucicaut. A Maternidade Baudelocque, descrita como estabelecimento-modelo, pode parecer uma maternidade assassina, onde a tendência ao recuo da mortalidade era pouco acentuada. Acontece que ela não internava todas as mulheres consultadas, mas acolhia prioritariamente os casos difíceis, como os das mulheres atingidas por tuberculose, que eram hospitalizadas em um pavilhão especial (a gravidez era um agravante da doença, e, das 100 primeiras hospitalizadas, 40 morreram) ou das que necessitavam de uma cesariana, operação que continuava com índices elevados de morte apesar dos progressos

\footnotetext{
${ }^{23}$ Numerosas fontes evocam aqui e ali a mortalidade das mulheres em trabalho de parto. A Associação Francesa das Mulheres Médicas dedica a esse assunto, em 1937, inúmeras reuniões de trabalho, e R. QUILLE-CHAYE, diplomada em higiene e em educação física, dedica a essa questão sua tese de medicina, defendida em 1939: Etude médico-sociale de la mortalité maternelle.
} 
realizados (entre $6 \%$ para a cesariana baixa e mais de $20 \%$ para a cesariana seguida de exposição temporária do útero).

Por outro lado, a Maternidade Baudelocque parece que recorria pouco à anestesia ou à analgesia, consideradas práticas perigosas, contrárias ao 'ato fisiológico' do parto, utilizadas abusivamente pelos médicos ingleses. A despeito do interesse manifestado, nos anos 1930, pela Associação Francesa das Mulheres Médicas (Association Française des Femmes Médecins), pelo 'clorofórmio da rainha' ou pelo método de preparação física e mental da fisioterapeuta britânica Margareth Morris, ${ }^{24}$ a dor e os gritos que acompanhavam o parto eram considerados, pela maioria dos médicos da época, como sinais característicos do parto. A dor era também valorizada em uma cultura católica partilhada, por exemplo, por Alexandre Couvelaire, que declarou em 1933, no $8^{\circ}$ Congresso da Associação dos Ginecologistas e Obstetras, o seguinte: "de minha parte, guardo ainda toda a minha ternura pelas mulheres que, cheias de esperança e de jovial serenidade, esperam sem temor a hora das supremas dores e as aceitam com vontade por vezes estóica, para serem as primeiras a escutar o primeiro grito do ser que elas alimentaram com seu sangue; não deixemos acabar esta fonte de profunda alegria, abstenhamo-nos de cultivar sistematicamente o desejo de soluções rápidas com hora marcada, no sono das anestesias gerais; não façamos nada que contribua para diminuir a beleza moral das mães e das crianças".

Assim, a partir do momento em que a febre puerperal foi contida pela prevenção e pelo isolamento, a medicalização certamente pode ser vista como mais segura, sobretudo no caso de complicações. Porém, muitas questões foram negligenciadas, como o sentimento, não de dor, mas de solidão e de submissão à autoridade médica, vivido pela parturiente. Não se pode esquecer que a medicalização do parto (no sentido estrito de um parto no hospital) teve uma importância menor no recuo global das taxas de mortalidade materna do que a medicalização da maternidade no sentido amplo, medicalização que se estende da procriação ao desmame, graças aos dispositivos implantados pelos estabelecimentos hospitalares e às consultas gratuitas ou particulares instaladas na cidade; o acompanhamento do pré-natal permitiu, aliás, baixar a taxa global de mortalidade de 44 por mil em 1922, para 35 por mil em 1938. ${ }^{25}$ Por fim, esse recuo da morte das mulheres no parto esbarrava em uma série de problemas médicos e sociais: falta de antibióticos ou de controle dos riscos operatórios; insuficiência da rede de consultas pré-natais; ausência de legislação sobre os trabalhos perigosos ou intensivos dados a mulheres grávidas; pobreza de numerosas famílias, agravada pela crise econômica dos anos 1930; insuficiência da proteção social da maternidade (somente um terço dos nascimentos eram cobertos pelo seguro-maternidade no fim dos anos 1930, e a licença-maternidade resultava em uma diminuição salarial dificilmente aceitável para muitas). Isso sem contar o hábito cultural de não se queixar e de considerar que a gravidez não necessita de nenhum cuidado especial. A análise da mortalidade infantil leva a conclusões semelhantes.

Antes da lei de 12 de novembro de 1945, sobre a proteção materna e infantil, adotada no quadro das reformas democráticas do pós-guerra e que previa uma consulta

\footnotetext{
${ }^{24}$ Aspiração pelo nariz de uma pequena dose de clorofórmio no início da contração, o 'clorofórmio da rainha' é assim chamado porque foi utilizado pela rainha Vitória no nascimento de seu oitavo filho, em 7 de abril de 1853 . 0 método de Margareth Morris, muito parecido com o método mais conhecido de G. D. Read, consiste em ensinar às mulheres grávidas o relaxamento e a descontração respiratória e em informá-las dos mecanismos corporais da dilatação, da expulsão e do fim do parto.

${ }^{25}$ A taxa de mortalidade é o número de crianças mortas no nascimento por mil crianças nascidas vivas e nascidas mortas. As comparações devem ser cautelosas porque certos autores incluem os embriões no cálculo.
} 
pré-natal por 20 mil habitantes e uma consulta de recém-nascido por 8 mil habitantes, os serviços de controle das futuras mães e dos bebês eram, como já dissemos, muito desiguais. É o caso de consultas de recém-nascidos em que atuavam numerosas associações privadas ${ }^{26}$ cujo trabalho, vale ressaltar, nem sempre era em colaboração com os serviços públicos das comunas, dos departamentos ou hospitalares. A colaboração entre as associações privadas e os serviços públicos para exames de saúde sistemáticos da população interessada só ocorreu em alguns departamentos ou cidades, como na AlsáciaLorena anteriormente alemã, no Sena, na Gironda ou nas grandes aglomerações de Lyon e Marseille. Apesar da criação, em 1938, de uma caderneta de saúde para cada recémnascido, o controle foi lento, e o recuo da mortalidade infantil permaneceu baixo e mal distribuído.

Em menos de 40 anos, a mortalidade infantil ${ }^{27}$ caiu para menos da metade, passando de 142 por mil em 1901, para 66 por mil em 1938, decrescendo com altos e baixos, até o fim dos anos 1920 (96 por mil), e ficando depois mais regular. Porém, o recuo foi menos acentuado do que em outros países da Europa, então dividida, em 1938, entre países com alta mortalidade (Europa meridional, central e balcânica, onde a mortalidade era igual ou superior a 100 por mil), países com taxa média (em torno de 60 por mil: França, Dinamarca, Bélgica, Alemanha), países com baixa taxa (abaixo de 50 por mil: Suíça e Europa do norte). A França ocupava apenas o oitavo lugar, e a comparação com a Holanda era vista como muito desfavorável. Em 1901, a Holanda apresentava mais mortes do que a França, mas a partir de 1913 tomou um impulso crescente, atingindo, em 1938, uma das mais baixas taxas de mortalidade infantil do mundo (com a Nova Zelândia): 36 por mil.

As causas da mortalidade também mudaram. No início do século $X X$, as três principais causas de mortalidade infantil eram, por ordem, a gastroenterite e as afecções digestivas, a debilidade congênita, e a broncopneumonia e as doenças respiratórias. Em 1935, a alta taxa de mortalidade estival deu lugar a uma alta taxa de mortalidade hibernal, causada pelas afecções respiratórias. A gastroenterite era a quarta causa de mortalidade, depois da debilidade congênita (três vezes mais mortal), as doenças respiratórias (duas vezes mais) e as afecções do sistema nervoso.

A taxa média de mortalidade infantil encobre grandes disparidades relativas ao sexo (alta taxa de mortalidade dos meninos), à condição social da criança (enorme taxa de mortalidade de filhos ilegítimos) e ao local de nascimento. Para o conjunto da população, a mortalidade nos dez primeiros dias era elevada e resistiu aos progressos verificados; esta parte da mortalidade infantil cresceu, passando de 15 a $20 \%$ nos anos 1920 , para 20 a $25 \%$ nos anos 1930 . Os filhos ilegítimos ( $10 \%$ dos nascimentos em $1920,6 \%$ em 1938, e taxa bem maior nas grandes cidades) não morreram em maior quantidade ou apenas mais nos primeiros dias do que os outros recém-nascidos. A distância acentuou-se posteriormente porque eles sofriam as difíceis condições de vida de suas mães ou eram confiados, abandonados, a amas pouco escrupulosas e pouco cuidadosas. Algumas creches, criadas por associações particulares, tentavam oferecer mais segurança aos pequenos abandonados ou se encarregar dos filhos das mães trabalhadoras.

A taxa de mortalidade infantil variou conforme as regiões, como mostram as estatísticas departamentais do Mouvement de la Population (Movimento da População).

\footnotetext{
${ }^{26} \mathrm{Na}$ França, Evelyne Diebolt, historiadora das associações e do lugar das mulheres nessas associações, é a autora de diversas monografias e de uma síntese publicada recentemente: DIEBOLT, 2001.

${ }^{27}$ A maior parte das conferências ou artigos de médicos e de numerosos políticos faz alusão à mortalidade infantil. A referência mais completa é, entretanto, CANDIOTTE CH., MOINE M. e Cl., 1948.
} 
Nos anos 1920, os departamentos urbanizados e industrializados tinham taxas altas; dez anos mais tarde, eles desapareceram da triste lista, embora os departamentos com taxas de mortalidade menores fossem as zonas rurais do Centro e do Sudoeste. Nascer em uma grande cidade não parecia mais ser um dado desfavorável, bem pelo contrário. A mortalidade infantil em Paris, que possuía um bom sistema de atendimento, era, em 1937, de aproximadamente 57 por mil, taxa inferior à média nacional; porém, a desigualdade social diante da morte continuava grande, com fortes disparidades entre o Oeste rico e os bairros mais pobres do Norte e do Leste. Em Saint-Etienne, também, as consultas de recémnascidos, cada vez mais freqüentes nos anos 1930, tiveram um efeito muito positivo (salvo em casos de epidemia) e foram ponto de honra na Exposição da Infância, em maio de 1933, onde se debateu muito o papel da mãe na luta contra a mortalidade infantil. Na realidade, as mães que deixaram poucas referências diretas parecem, ao mesmo tempo, desejosas de cuidados para seus filhos e desgostosas com as imposições dos profissionais de saúde e das senhoras das associações filantrópicas, que incitavam ao aleitamento materno e as desqualificavam pela 'sua ignorância e negligência', para impor regras estritas de puericultura, baseadas em prescrições (quantidade de mamadas, peso da criança...).

O período entre as duas guerras na França é freqüentemente considerado pelos historiadores como um período homogêneo e bem individualizado, sobre o qual o discurso histórico se escreve em função do acontecimento posterior que é a Segunda Guerra. Como propôs recentemente a britânica Siân Reynolds, ${ }^{28}$ uma abordagem de gênero, centralizada nas mulheres e nas relações de sexo, permite uma outra leitura, mais próxima do cotidiano dos contemporâneos que não conheciam o futuro. Observar as múltiplas facetas, as conseqüências e os limites da "medicalização" do parto inscreve-se nesse renascimento historiográfico.

Na história da medicalização da maternidade, esse fenômeno que caracteriza o século XX, com suas continuidades e suas rupturas, delineou-se e ganhou forma entre os anos 1919 e 1939, apesar das resistências e dos bloqueios. O movimento de transferência das parturientes para as maternidades cresceu após 1945, assim como ocorreram transformações na profissão de parteira (condições salariais e diminuição do número de profissionais). Verdadeiro direito social e prioridade nacional, a PMI (Proteção Materna e Infantil - Protection Maternelle et Infantile) - a sigla impõe-se quando se fala das estruturas de proteção materna e infantil - associou seus efeitos aos progressos da medicina e à melhoria geral das condições de vida para vencer a morte das parturientes e dos bebês. Porém, a partir dos anos 1970, esse movimento de medicalização deparou-se com a contestação do poder médico e com as reivindicações das mulheres para disporem de seus corpos. Hoje, desenha-se uma nova configuração que alia, de modo geral, segurança, conforto e respeito às individualidades.

\section{Referências bibliográficas}

BEAUVALET-BOUTOUYRIE, Scarlet. Naître à l'hôpital au XIX siècle, Paris, Belin, 1999.

CAHEN, Georges. L'autre guerre, Paris, 1920.

CANDIOTTE CH., MOINE M. e Cl., La mortalité de l'enfant de première année, Institut national d'hygiène, tomo $51, \mathrm{n}^{\circ} 12,1948$.

COUVELAIRE, Alexandre La nouvelle maternité Baudelocque, Paris, 1930.

COVA, Anne. Maternité et droits des femmes en France (XIXe-XXe), Paris, Anthropos, 1997.

${ }^{28}$ REYNOLDS, 1996. 
CRIVELLI, Philippe. La protection maternelle et infantile en milieu rural, tese de medicina, 1948.

DIEBOLT, Evelyne. Les Femmes dans l'action sanitaire, sociale et culturelle, 1901-2001. Les associations fece aux institutions, Femmes et Associations, 2001.

DUBESSET, Mathilde, ZANCARINI-FOURNEL, Michelle. Parcours de femmes, réalités et représentations. Saint-Etienne, 1880-1950, Lyon, Presses universitaires de Lyon, 1993.

GAUTIER Xavière. Naissance d'une liberté. Le grand combat des femmes au XIXe siècle, Paris, Robert Laffont, 2002.

GÉLIS, Jacques. La sage-femme ou le médecin. Une nouvelle conception de la vie, Paris, Fayard, 1988.

KNIBIEHLER Yvone. La Révolution maternelle depuis 1945. Femmes, maternité, citoyenneté, Paris, Perrin, 1997.

MOSSUZ-LAVAU, Janine. Les Lois de l'amour. Les politiques de la sexualité en France (19501990), Paris, Payot, 1991.

QUILLE-CHAYE, R. Etude médico-sociale de la mortalité maternelle, tese de medicina, 1939. REYNOLDS, Siân. France between the Wars. Gender and Politcs, Routledge, 1996.

THÉBAUD, Françoise. Quand nos grand-mères donnaient la vie. La maternité en France dans l'entre-deux-guerres, Lyon, Presses Universitaires de Lyon, 1986.

Tradução de Maria Helena Gallotti

Childbirth Medicalization and its Consequences: The Example of France between the Two
World Wars
Abstract: In the history of childbirth medicalization, the years between the two world wars (19191939) appear in France as a transitional period. In a context of low birth rate, particularly in great towns, an increasing number of pregnant women begin to move to maternity hospitals, which offer an increasingly better care. At the same time a network of pre and postbirth care is developed to supervise pregnancy and nursing. The purpose is to save mothers and especially children. While midwives feared the decline of their profession, the objective was only partially reached, for the medicalization of childbirth and of the maternal function met with limits and a lot of resistance: the weight of social and cultural habits, the insufficient social protection of motherhood, the difficult living conditions of certain classes, the lack of a network of medical appointments for pregnant women and for the new-born, a very unequal distribution of such services throughout France, the liberal beliefs of the medical professions and the fear of State intervention...

Key words: childbirth, hospital maternity, midwife, pre and postbirth care, infantile and maternal mortality. 